J. Med. Microbiol-_Vol. 41 (1994), 448

(C) 1994 The Pathological Society of Great Britain and Ireland

\title{
ANNOUNCEMENT
}

\section{Update on Tuberculosis}

Saturday 4th February 1995

To be held at Liverpool School of Tropical Medicine

Programme:

$9.00 \mathrm{am}$ : Registration

- Morning session: Chairman, B. I. Duerden

- Taxonomy of mycobacteria (P. A. Jenkins), Molecular diagnosis and molecular epidemiology (B. Watt), Molecular basis of antimicrobial resistance (Young), Tuberculosis in children (B. Coulter), Tuberculosis in adults (P. Davies), Tuberculosis and AIDS (C. Gilks)

- Afternoon session: Chairman, C. A. Hart

- New aspects of chemotherapy (G. Tillotson), Immunoprophylaxis and immunotherapy (P. Fine, J. Stanford)

- Closing remarks (N. Beeching)

Further information from:

Professor C. A. Hart

Department of Medical Microbiology,

University of Liverpool,

PO Box 147,

Liverpool L69 3BX. 